\title{
THE CONCEPT OF POWER IN TEACHER TALK IN CONTEXTUALITY OF TEACHER'S AUTHORITY
}

\author{
Kristine Jozauska \\ University of Latvia, Latvia
}

\begin{abstract}
Education has been accepted as one major agency of socialization, and teachers and educational institutions as socializing agents. Teachers are looked upon as the individuals who can help to bring about positive changes in the lives of people. The role of the teacher has changed. Teachers do not see themselves as powerful. Imagining teachers as the most powerful creatures in the class seems plausible, but how is power relation represented in teacher's discourse? The way teachers see themselves as professionals and how they compose their identities in schools is important factor in teacher authority discourse. The problem of the social status of the teacher cannot be solved instrumentally by increasing the disciplinary power of teachers, but must be addressed as a more foundational problem concerning the basis of authority in a pluralistic society. The discussion on how power is activated, practiced and accomplished within and across children's everyday interactions with adults, is in great significance. Language plays an important role in authority constructions. Teachers' ability to control their use of language is considered to be as important as their ability to select appropriate methodologies.
\end{abstract}

Keywords: teacher talk, power, teacher authority.

\section{Introduction}

The world we leave to our children depends in large measure on the children we leave to our world. The world's hopes for the future rest with today's young people and their readiness to take up the challenges of the coming century. Education is seen as major vector in society. On the threshold of the twenty-first century, the education of the young has never been more in need of our commitment and resources. Our teachers have never been more crucial to our collective future.

The young generation is entering a world which is changing in all sphere. As an institution, the education system plays a key role in transmitting dominant ideologies of society (Clark, 2005). One of the ways it does this is through the reproduction and maintenance of a standard variety of a language through which, in turn, notions of national and cultural identity 
are transmitted. The purpose of education is to initiate the young into the different ways in which, over the centuries, men have organized their experience and understanding of the world and to lead the individual to empowerment and social- emotional development. The person who offers the guidance, judgment and knowledge is the teacher.

\section{Research problem}

Education has been accepted as one major agency of socialization, and teachers and educational institutions as socializing agents (Patil, 2012). Teachers are looked upon as the individuals who can help to bring about positive changes in the lives of people. They are seen as natural leaders who can give advice on various affairs in the community. William H. Kitchen (2014) gives a view of education as a process that liberayes through the guidance and leadership of authority. In this version of knowledge-driven education, the teacher's authority should be absolute, so as to ensure that the teacher has the scope to liberate his students.

The success of being educated depends upon the ability of teacher to explain and inspire, and on the willingness of the young to engage. The discussion on the role of authority in knowledge development and the subject of lack of teacher's authority is in great tension. Teachers do not see themselves as powerful. The discussion on teachers' loss of authority is today taking on a totally new dimension. The role of the teacher has changed. From the former "man of repute" the teacher has become a service provider mistreated both by the media and by his students.

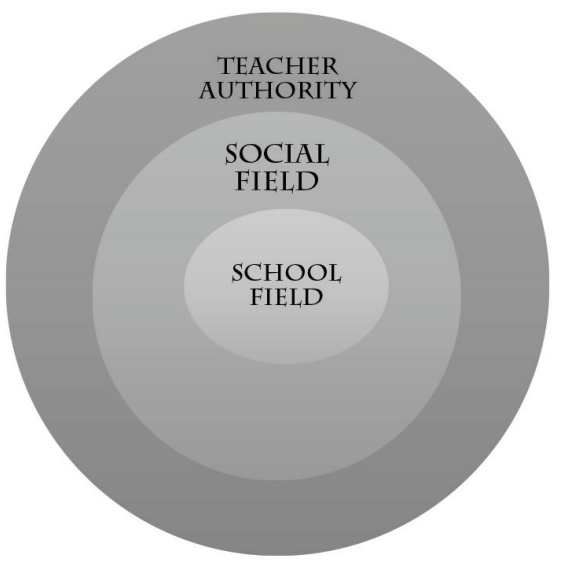

Figure 1. Teacher authority in fields

The issue of authority in education has been explored in some depth by various scholars. The problem of the social status of the teacher cannot be 
solved instrumentally by increasing the disciplinary power of teachers, but must be addressed as a more foundational problem concerning the basis of authority in a pluralistic society (Dahlbeck, Lilja, 2016). It is important to have a view of knowledge transmission and teacher-student relations in the fast-changing world in which we live. The phenomenom of teacher's authority is intricated (see Figure 1) to the social and school fields, and it is its complexity (Cortizo, et al 2015). Figure 1 shows the school field inserted in the social field, suffering direct interference from economic, political, cultural and social in a diachronic and synchronic way. However, the specifics of school field distinguish it from other fields, because it is governed by communicational logic, that is given in a process where different people play different roles. Schools are complex spaces of social interaction for excellence. They are spaces of relation and communication. The relational and communicational features of this space, whose protagonists should share languages, affections and experiences in their daily life (Ferreira in Cortizo, et al 2015). Teachers as the most powerful creatures in the class seems plausible, but how is power relation represented in teacher's discourse? It calls on a necessity to investigate how this power is linguistically expressed by teachers and presented in the classroom. The discussion on how power is activated, practiced and accomplished within and across children's everyday interactions with adults, is in great significance.

Richmond and McCroskey (Richmond and Mc Croskey in Richmond, 2009) reviewed different studies on and came to the conclusion that these studies are based on the premise that:

a) the role of a teacher, almost by definition, involves a social influence;

b) the use of power is built into the job of a teacher;

c) a teacher must have considerable amount of power to create the environment conducive to learning;

d) for teacher power to exist, it must be granted by the students.

Teachers' knowledge and institutional status shift from the symbolic level to the social level of power and dominance mainly through the medium of discourse. An analysis of the teacher's discourse may reveal the details of the daily constitutive practices of power and authority (Wenren, 2014).

For Bernstein, the pedagogic discourse embeds the discourse of specialized competencies to be acquired, that is, what learners are to learn, in the discourse which creates and regulates social order. Pedagogic discourse specifically frames classroom discourse within a context of both power relations and moral values by revealing how the instructional discourse is embedded in the regulative discourse (Clark, 2005).

This paper reviews ideas of concept of power in teacher talk in contextuality of teacher's authority. It's a part of an ongoing PhD research, 
literature review was used as method assisting understanding and interpreting the context of studied subjects.

\section{Contextuality of the phenomenon of authority}

The scientific literature indicates the need to pay attention to different aspects changing educational field and culture in building the contextuality of the phenomenon of authority.

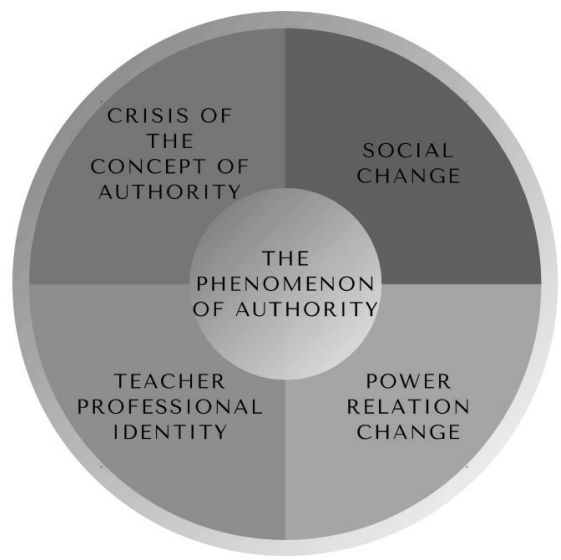

Figure 2. Contextuality of the Phenomenon of Authority

In the process of conceptualization the phenomen of authority it has come clear that there are some important aspects making context in which authority of the teacher forms (see Figure 2 author's concept):

a) Crisis of concept of authority. Concern with authority is as old as human history itself. The modern world attempted to develop new foundations for authority - democratic consent, public opinion, science - Furedi (2013) shows that this problem has remained unresolved, arguing that today the authority of authority is questioned. The discussion is important: How do you have order in a world where people have different interests, and where religion can no longer provide a narrative or consensus? How do you get people to cooperate and to abide by a certain set of shared assumptions? The problem of order, of what morally grounds society, used to be the main subject many political thinkers dealt with. But now, as Furendi (2013) argues, the problem of order has been redefined in a more narrow technical sense, as a problem of social cohesion, for instance, or as a problem of trust. The break with tradition and the past as a source of authority - this seems to be a key turning 
point in the conception of authority. From the "man of repute" a person above suspicion and beyond criticism, the teacher has become a service provider mistreated both by the media and by his students.

b) Social change. Social change takes place as a response to many types of changes that take place in the social and non-social environment. Education are all built on the assumption that learning is closely linked to personal and social change (Bourn, 2015). Education can initiate social changes by bringing about a change in outlook and attitude of man. It can bring about a change in the pattern of social relationships and thereby it may cause social changes. According to Patil (2012) in describing education as an instrument of social change, three things are important: the agents of change, the content of change, and the social background of those who are sought to be changed, i.e. students. Education can be used as a tool to empower the individual. Therefore, teacher's role as agents of social change is in great tension. Teachers are looked upon as the individuals who can help to bring about positive changes in the lives of people. Within these discourses and practices, the role of the teacher as the agent for promoting these changes is often assumed but rarely discussed as to what it means. The question is: what kind of adult authority is appropriate for free and pluralistic society?

c) Power relation change. Authority concept has close relation with the concept of power and influence. Authority means legitimate power. Power can be defined in variety of ways. Michel Foucault (2001) has been hugely influential in shaping understandings of power, leading away from the analysis of actors who use power as an instrument of coercion, and even away from the discreet structures in which those actors operate, toward the idea that 'power is everywhere', diffused and embodied in discourse, knowledge and "regimes of truth". Foucault (2001) is one of the few writers on power who recognise that power is not just a negative, coercive or repressive thing that forces us to do things against our wishes, but can also be a necessary, productive and positive force in society. Power is also a major source of social discipline and conformity. Power is the possession of authority, control, or influence by which a person influences the actions of others. One of the acknowledgments in new paradigm in describing childhood and adult-child relationships, is that children are active agents who are not simply shaped by the world around them but actively shape and change that world. Relationships between adults and children generate fields of negotiation and renegotiation where norms and expectations are actively challenged 
and modified. Children adopt a host of multiple strategies in their dealing with adults, at times complying with or resisting adult control over their daily lives. Children interact with adults to produce negotiated outcomes. They make sense of and interpret their everyday interactions with adults. Within these interactions with more powerful actors, children strive to achieve elements of social control over their daily environment, power to make and shape decisions about their everyday lives. This focuses on necessitaty to revisit structured power relationships between adults and children (Leonard, 2015). The discussion on how power is activated, practised and accomplished within and across children's everyday interactions with adults, is in great significance. There are many important aspects in analyzing power relations among students- treachers, for example how power is exercised and resisted in various aspects of an academic situation in pedagogy. Parents and teacher now know that they have no control over the child; they only can control themselves and the resources at their disposal. Their authority manifests itself when they conscientiously use the means at their disposal, so as to best fulfill their responsibility (Omer, 2011). In promoting the new authority, we no longer focus on the reactions of the child, but rather on the actions of the adult. Cooperation has become a choice.

d) Teacher professional identity. Classroom is a preliminary stage for educational activities and it is a position for preparing people for living in a changing world. Classroom is a place that some direct services are provided for students so that they develop individually and socially and the requirement for healthy and holistic society development can be provided. Instruction or class management is a part of education and is referred as a part of educational activities that takes place with presence of the teacher in classroom. Therefore class management can be considered as an important indicator in teachers' task is a complicated take that is referred as an "art" (Esmaeili, et al 2015). The role of the teacher and its management style is highly important and essential for succeeding in educational objectives of students in proportion of today world. The way teachers see themselves as professionals and how they compose their identities in schools is important factor in teacher authority discourse. Challenges of modern society including school requires changes in conceptual approach of pedagogical sciences for interpretation of modern social phenomena. Situational and social challenges, in and out of the classroom, in the educational landscape that is located in a township or urban community, shape the identity of our teachers. Teaching has become so difficult, simply because of 
the circumstances teachers face, which are way out of their control (Smit \& Fritz, 2008). Authority is one of the core constituents of the professional identity of the teacher and an essential guarantee of effective classroom management and instruction (Wenren, 2014).

\section{Why authority is needed- Dewey's ideas}

Authority involves power, to produce and to regulate a certain kind of behaviour. Authority is connected with the rule-governed form of social life. The importance of moral education and teachers' moral authority has long remained the central feature of any education. Schools has responsibility for children's moral and intellectual development. Teaching itself involves moral action, classroom interaction is fundamentally moral in nature.

Dewey's (1987) ideas on authority reveals that authority stands for stability of social organization by means of which direction and support are given to individuals; while individual freedom stands for the forces by which change is intentionally brought about. The issue that requires constant attention is the intimate and organic union of two things: of authority and freedom, of stability and change. Dewey therefore believed that there is an intimate connection between the principle of freedom and the principle of authority. In a healthy society, he believed that individuals were in need of authority as much as they were in need of freedom. In this regard, the real problem is not to separate but rather to find out the proper relationship between them so that better understanding and action can come about in experience. Dewey placed authority in the method of organized intelligence as exemplified in the area of science. By elevating scientific intelligence to the status of authority, he viewed authority to be intellectual, not dogmatic as earlier centuries sought (Kim, 2013). Intelligence is the power to think of available information and acquired knowledge with deliberate reflection and to relate them to current issues in experience. It is also the ability to frame worthwhile aims and organize a means to carefully execute and realize them. The business of a teacher, Dewey argues, is to help students to develop such intelligence and continually increase in that power.

According to Dewey (1987), effective educational authority is to be exercised in a social context, where individuals, including the teacher, are involved and contribute to and participate in its common activities and understandings. In this way, Dewey insists that the principle of social control does not necessarily restrict the principle of personal freedom. Moreover, under such a condition, where the un- coerced consensus of social control prevails, he maintains that individuals in the classroom community, especially children, do not feel that they are submitting to external imposition even if they are called to order. 


\section{Language role in authority construction}

There are many aspects of skilled professional practice that can be made explicit and which can help teachers to work more effectively, with even the most challenging young people.

Teacher talk is a powerful classroom tool to convey and construct meaning, to clarify understanding how teacher experience and talk in pedagogical situations. Teachers' ability to control their use of language is considered to be as important as their ability to select appropriate methodologies (Walsh, 2002).

In any interpersonal context, control over the use of physical and visual space communicates powerful messages about status and authority. Teachers' non-verbal behaviour will be a means of demonstrating their confidence and sense of professional authority (Reynolds, 2014).

What becomes the content of a school subject is not something unique or logical, but is defined by what those who regulate and control the curriculum believe to be the most useful and desirable to benefit society. Language is used to construct power relations. People may build power relations by establishing social categories. Teachers' words and the way they use them create meaning for students as well as themselves. Words acquire meaning only in human interaction in particular contexts and situations (Maftoon, Shakouri, 2012). From a Marxist point of view, as reported by Wodak (2001), language is not powerful on its own - it gains power by the use, powerful people make of it. Along the same vein, Jones (2007) says, "words don't produce or interpret themselves; people, engaged over some matter, are responsible for that". Language is not a word we may use to refer to the creative communicative endeavours of particular individuals, but the term for an abstract, self-contained system of forms, meanings, and rules whose existence is the precondition for successful acts of linguistic communication, any such act being the mere realization or expression of elements or rules in the system (Jones, 2007).

As Jones (2007) points out, to engage communicatively with someone is a form of conduct towards them, a way of treating them, and is, therefore, as is any form of human behaviour, an irreducibly moral act in the broad sense of the word, whether this is to do with the personal morality of rights and responsibilities. A successful educator in the field of teaching should be aware of the power of words and its impact on the audience and avoid using words habitually without thinking. Also, ordering is one of the conflicts which leads to failure in human interaction. The teacher should express his opinion with proper words and within the defined framework for his comments to be effective and penetrating. Therefore, the teacher, as the sender of the message, should first determine 
the framework of his message and then express his expectations of the students frankly with appropriate tone and words (Gholipour, 2007). In the selection of words, the intended concept must be exactly in the words of the educator. It is appropriate to use clear, concise, accurate, polite, correct and rich expression in oral communication with the audience to transmit the speaker's intentions to the audience proper (Najafi, Rahmanzade, 2013).

In a democratic education the concept of power is shared. In this realm of philosophy, it is suggested that teachers should avoid displays of power to command in their classes so as to reduce the gap between them and students, which will surely help students to be more active in participating activities in class (Yanfen, Yuqin, 2010).

According to literature review, I have found some subjects to be indicators in analysing power relations which can be implemented in making observation protocol for the part for ongoing $\mathrm{PhD}$ research. Those indicators are:

a) Social cognitive aspect: through the analysis of the topics that people talk about, concludes that they represent the things that exist in their minds. Managing the mind of others is essentially a function of text and talk. Considering Van Dijk (1993) power is mostly cognitive, and enacted by persuasion, dissimulation or manipulation, among other strategic ways to change the mind of others in one's own interests. Walsh (2002) examined the ways in which teachers construct or obstruct learner participation in classroom interaction, through their choice of language. By construction he meant "increasing learning potential" which he claimed can be done through activities like, direct error correction, content feedback, checking for confirmation, extended wait time and scaffolding. Obstruction was defined by him as "reducing learning potential" which according to him, can be done through turn completion, teacher echo, teacher interruptions.

b) The class arrangements as signs of power (Benesch, 1999). Conceptual framework for questions about authority and control such as: what are students permitted to do in a particular setting? How do they respond to rules and regulations? How are decisions about control and resistance made? What is the way teachers present themselves and way instruction is carried out.

c) Body as a site of control (Fuko, 2001). The ways institutions regulate the body. The key feature of disciplinary power is that it is exercised directly on the body. According to Fuko (Foucault) power can also be said to create knowledge in the sense that institutions of power determine the conditions under which scientific statements come to be counted as true or false. 
d) Teachers as moral agents (Bergem, 1990; Johnston, et al1998). How moral values are played out in the classroom, moral dilemma and decision making. Moral dimensions of teaching. Moral sensibility means gaining a deeper understanding of interactions in classroom.

e) Nonverbal behaviour. Nonverbal expressiveness is understood as the demonstration of behaviours that communicate energy, passion, and interest in teaching. The effective use of expressive nonverbal behaviours can positively influence a students' relationship with their teacher and their interest in the subject matter (Reynolds, 2014). Teacher intensity, enthusiasm, and perceived warmth are teacher personality attributes associated with effective teaching (Erbes, 1983). Teacher warmth, like enthusiasm, is conveyed through nonverbal means in the classroom and has been positively associated with student learning (Voelkl, 1995). Teachers who create a warm and inviting classroom provide an atmosphere conducive to learning (Stronge, et al 2007).

\section{Conclusions}

Teacher quality and authority are most important factors influencing learner outcomes. The traditional differential categorizations of "knowledge", the "teacher" and the "learner", as well as traditional ways of learning are challenged. This challenge obliges teachers to reflect on where their authority comes from, what kind of professional identity they wish to take, and what kind of relationship they wish to build with students (Wenren, 2014).

Language is used to construct power relations. Teachers use to explain, justify and make sense of themselves in relation to the students, and of education at large. Through the evaluation of their discursive choices and modes of presentation, the positioning of teachers can be seen to impact the most essential parts of the teaching process (Wenren, 2014). The strong and weak forms of authority can be illustrated through the importance that teachers ascribe to the claim of their desired identities. The strong form, framed through a high degree of certainty and discursive force about the teachers' high status and social position, reveals their insistence on the traditional role. As Wenren (2014) concludes, the strong form stresses knowledge, order, correctness, unitary proposition, timing, evaluation, etc. A strong form of authority is more consistent with the enduring power characteristics of institutional discourse and more resistant to the dynamics of local interaction. Knowledge is presented as absolute, hierarchical and decontextualized. A weak form of authority is characterized by low or middle modality verbs, low graduation, and an absence of extreme 
expressions. Teachers may refer to friends and partnerships, but they are cited to relate with students or to tone down the teachers' importance.

As with many other aspects of teaching, the effort to understand the tensions of authority is important in itself. Authority is a constant in teaching; the authority of the teacher, and the relations of power and morality that underlie it, should then be a source of continual reflection.

\section{References}

Benesch, S. (1999). Rights analysis: Studying power relations in an academic setting. English for Specific Purposes, 8(4). 313-327.

Bergem, T. (1990). The teacher as moral agent. Journal of Moral Education, 19. 88-100.

Bourn, D. (2015). Teachers as agents of social change. International Journal of Development Education and Global Learning, 7 (3), 63-77.

Clark, U. (2005). Bernsten's theory of pedagogic discourse: Linguistics, educational policy and practice in the UK English/literacy classroom. English Teachinh: Practice and Critique, 4 (3), 32-47.

Cortizo, T.L., Ferreira, E., Ornellas, L. (2015). Teacher authority in the modern era: questioned pedagogical act. Teacher Education. 630-638.

Dahlbeck, J., Lilja, P. (2016). The Concept of Authority and the Swedish Educational Crisis. Philosophy of Education Yearbook 2016, ed. Levison, N.

Dewey, J. (1987)."Authority and Social Change." In John Dewey: The Later Works. vol. 11. Edited by Jo Ann Boydston. Carbondale: Southern Illinois University Press, 1987. (Original work published 1936).

Erbes, R. L. (1983). Certification practices and trends in music teacher education, 1982-1983. Music Educators National Conference. Retrieved from: www.nafme.org.

Esmaeili, Z., Mohamadrezai,H. \& Mohamadrezai, A. (2015). The role of teacher's authority in students' learning. Journal of Education and Practice, 6 (19), 1-15.

Fuko, M. (2001) Uzraudzìt un sodīt. (Discipline and Punish) Omnia Mea, Rīga.

Furedi, F. (2013) Authority: A Sociological History. Cambridge University Press.

Gholipour A. (2007). Pathology of teacher-student relationship from the perspective of teachers and secondary students in the city of Parsabad. Persian.

Johnston, B., Juhasz, A., Marken, J., \& Ruiz, B. R. (1998). The ESL teacher as moral agent. Research in the Teaching of English, 32. 161-181.

Jones, P.E. (2007). Why there is no such thing as "critical discourse analysis". Language \& Communication, 27 (4), 337-368.

Kim, S.H. (2013). The Problem of Authority: What Can Korean Education Learn From Dewey? Education and Culture, 29 (1), 64-83.

Kitchen, W.H. (2014). Authority and the teacher. Bloomsbury Academic.

Leonard, M. (2015) The Sociology of Children, Childhood and Generation. SAGE Publications. 
Mafroon, P., Shakouri, N. (2012). The concept of Power in Teacher Talk: A critical Discourse Analysis. World AppliedSciences Journal 19 (8), 1208-1215.

Najafi, T., Rahmanzade, A. (2013). The relationship between communication skills and educational effectiveness of teachers of girls in Valiasr Technical College in Tehran. Journal of media studies, 8 (4), 193-206.

Omer, H. (2011) The new authority. Family, school, and community. CAMBRIDGE University Press.

Patil, N. (2012). Role of Education In Social Change International Educational. E-Journal I (II), 205-210.

Reynolds, J.H. (2014). The Effect of Teacher Nonverbal Expressiveness on Ratings of Teacher Effectiveness and Student Learning.

Richmond, V.P. (2009). Communication in the classroom: Power and motivation. Journal Comminication Education, 39 (3), 181-195.

Smit, B., Fritz, E. (2008). Understanding teacher identity from a symbolic interactionist perspective: two ethnographic narratives. South African Journal of Education, 28, 91-101.

Stronge, J. H., Ward, T. J., Tucker, P. D., \& Hindman, J. I. (2007). What is the relationship between teacher quality and student achievement? Journal of Personnel Evaluation in Education, 20, 165-184.

Van Dijk, T. (1993). Principles of critical discourse analysis. Discourse and Society, 4. 249-283.

Voelkl, K. E. (1995). School warmth, student participation, and achievement. Journal of Experimental Education, 63 (2), 127-138.

Walsh, S. (2002). Construction or obstruction: teacher talk and learner involvement in the EFL classroom. Language Teaching Research, 6 (1), 3-23.

Warren, L.L. (2016). Viewing teachers as leaders without being administrators. Education, 136 (4), 508-514.

Wenren, X. (2014). The Construction of the Teacher's Authority in Pedagogic Discourse. English Language Teaching, 7(6), 96-108.

Wodak, R. (2001a). What CDA is about-a summary of its history, important concepts and its development. In R.. Wodak \& M. Meyers (Eds.) Methods of CDA (pp: 1-13). London: Sage Publication.

Yanfen, L. and Z. Yuqin, 2010. The study of teacher talk in interactions in English classes. Chinese Journal of Applied Linguistics, 33 (2), 76-8

Yuan, X. (2012). How to Deal with Student Misbehavior in the Classroom? Journal of Educational and Developmental Psychology, 2 (1), 144-150. 